\title{
Audit of child and adolescent psychiatry in a teaching hospital in Nigeria: Prevalence, pattern and implication for improved services
}

M F Tunde-Ayinmode, MB BS, FMCPsych

Department of Behavioural Sciences, University of llorin Teaching Hospital, Ilorin, Nigeria

Objective. This study aimed to identify the socio-demographic characteristics, pattern of psychiatric disorders and management of children and adolescents before the setting up of a dedicated child and adolescent unit at the University of llorin Teaching Hospital, llorin, Nigeria.

Method. A retrospective study, carried out at the Department of Behavioural Sciences of the hospital.

Results. The age range of the 94 children seen was $7-19$ years, with a mean of 16.38 years (standard deviation 2.49); $82 \%$ were aged $14-19$ years and $17 \% 7-13$ years, while only 1 child was under 7 years old. The majority of the children lived with their parents in monogamous families with 5 or more children. The majority of the parents were educated and gainfully employed.

The major diagnoses were schizophrenia $(50 \%)$, delirium $(15 \%)$ and seizure disorders (9\%). Of the patients $64 \%$ were managed as outpatients and $36 \%$ as inpatients. Drug therapy was involved in the majority of cases, and the most frequently prescribed medication was haloperidol, atypical antipsychotics such as risperidone being used in only $8 \%$ of cases.

Most of the patients were referred from the primary careassociated departments of the hospital, i.e. the general outpatient department $(40 \%)$ and the internal medicine and paediatrics departments (29\%). Referrals from welfare, judicial and educational institutions were uncommon $(3 \%)$.

Conclusion. The pattern of patient presentation and management had not changed to any great extent over the past two decades. The introduction of a child and adolescent psychiatric unit is expected to improve consultation/liaison psychiatry and also child psychiatric service delivery and research. Understanding of the prevalence and pattern of presentation of mental disorders and their management is also expected to help improve the strategic planning and organisation of the new clinic.

Child and adolescent psychiatry in developed countries is characterised by a well-organised and co-ordinated mix of service delivery facilities such as hospital, residential and day treatment units run by a multidisciplinary complement of professionals including psychiatrists, psychologists, counsellors and social workers. ${ }^{1-4}$ Systematic development efforts have created a surveillance system that includes parents, educational, judicial and medical institutions, and mental health professionals. By routine or incidental observations and/or use of screening or diagnostic instruments such as the Child Behaviour Scale or Kiddie-SADs this system ensures that the majority of children with psychiatric disorders are brought into the net of service delivery. ${ }^{1-4}$ Another important aspect of child psychiatry in developed countries is the variety and co-ordination of treatment modalities such as individual or group therapy, family therapy, behavioural therapy, hypnotherapy, pharmacotherapy and educational measures. ${ }^{1,3}$

In Nigeria, like most developing nations, the above is still not practicable, and poor services and poor attendance mean that both the demand and supply ends of child psychiatric services are underdeveloped. While there is ample epidemiological evidence that child psychiatric disorders are prevalent in Nigeria, ${ }^{5.8} \mathrm{few}$ children are brought to the health services because of mental health problems ${ }^{9}$ - even emotional and conduct disorders, which are known to be common in childhood. ${ }^{1,10}$

Globally, epidemiological and clinical studies suggest that the most common child psychiatric disorders are conduct/ oppositional disorders, anxiety/emotional disorders, mixed disorders of conduct and emotions, attention deficit hyperactivity disorders, major affective disorders, pervasive developmental disorders, specific developmental disorders, schizophrenia and other psychoses, enuresis, mental retardation and organic brain 
damage..$^{1-4}$ It is important to keep in mind that the pattern of child psychiatric disorders varies with age and changes as childhood progresses to adolescence. For example, schizophrenia, depression and drug abuse start or become more common in adolescence, whereas enuresis and some developmental disorders are less frequently seen. ${ }^{1,3}$ Schizophrenia is rare before puberty, and very rare before the age of 7 years. "I

In the clinical setting, the pattern of child psychiatric disorders presenting to the psychiatrist in Nigeria suggests a divergence from the general epidemiological trend. Characteristically, we most frequently see severe conditions or those that have resulted from brain damage, such as seizure disorders, mental retardation, developmental delays and autism, in younger children, 9,12,13 while severe adult-type disorders such as schizophrenia, other psychoses, and substance abuse present in older adolescents. ${ }^{14}$

The relative absence of children among both psychiatric inpatients and outpatients in Nigeria is not a new problem, the older literature also attesting to it. It has been reported ${ }^{15}$ that children also seldom presented with psychological problems in medical outpatient departments (paediatric and general outpatient departments). Annual rates of clinic attendance have generally been described as poor and the default rates at clinics were generally high. 9.12 It therefore seems that most of the management of emotionally and behaviourally disturbed children in Nigeria is done outside organised medicine and hospital and specialist care.

It is recognised that epidemiological prevalence does not translate to service utilisation by parents. For example, in the Isle of Wight study a substantial number of parents suggested that they would not use services even if they were freely available. ${ }^{2}$ This indicates that parents' views and those of psychiatrists and caring institutions may not be the same when it comes to issues such as diagnosis, severity of illness, needs and modalities of treatment. However, we need to organise our services along the lines of those in developed countries to help ensure that parents recognise problems and are willing and motivated to seek help. It is believed that changes in the quality and quantity of services provided are usually followed by changes in the people's attitude towards them, so the proportion that is not seeking help would be likely to change for the better if services were to increase or improve. $^{2}$

The reasons for the relative dearth of child psychiatric hospital cases in Nigeria are diverse, but inadequate health care resources and derisory allocation to the paediatric sub-sector stand out.
Poverty is a major factor contributing to low attendance rates in clinics. Inability to pay for orthodox care together with ready accessibility and lower cost of traditional services (coupled with their promise of permanent cure of problems) are also major factors. The lack of education and ignorance associated with poverty limit accessibility to vital information on the recognition and management of childhood psychiatric disorders. Ignorance of what constitutes psychiatric illness on the part of parents and sometimes health workers, ${ }^{10,17}$ and about the limitations of hospital care, contribute to low attendance and high default rates. ${ }^{9,12}$

Restrictive African cultures coupled with the generous use of corporal punishment limit children's ability to verbalise their emotional problems or seek help. ${ }^{14-16}$ Supernatural beliefs are rife in Nigeria, as in other parts of Africa, and stigma associated with mental illness may also limit reporting of mental illness in children - for example, behavioural problems such as stealing and lying are considered shameful, and may not be reported to the doctors. ${ }^{18.20}$ Furthermore, practices such as child labour, child marriage, or child sexual and physical abuse may not be reported because of cultural tolerance of them.

Also likely to contribute to low use of services is the shortage of specialised personnel such as speech therapists, child psychiatrists, psychologists, social workers and remedial teachers to assist in the management of disorders like mental retardation, speech difficulties, reading and writing difficulties, specific developmental disorders and educational under-achievement. When the parents of disturbed children whose hospital treatment has failed interact with parents of children with similar problems, the latter are unlikely to be encouraged to seek help.

The foregoing indicates that compared with developed countries, child psychiatric services in Nigeria are still underdeveloped in respect of both quality and quantity of human and infrastructural resources. Even now very few health institutions, including the teaching hospitals, have separate child psychiatry units, meaning that children are seen in and admitted to adult facilities; trained child psychiatrists are rare indeed, and other crucially important professionals are scarce. ${ }^{16}$ Child psychiatric units can play the role of a development agent in organisation of services in developing countries. By offering consultation/liaison services child psychiatrists can play a leading role. Without dedicated child psychiatric units it may be difficult to reverse the current trend of poor attendance, poor service and poor outcome for children with psychiatric disorders in Nigeria.

In the past few years attempts have been made not only to encourage sub-specialisation but to set up dedicated units for child 
and adolescent psychiatry. It is in this setting that the University of llorin Teaching Hospital (UITH) started a child and adolescent psychiatric unit in March 2007, and this study is an attempt to audit what had been happening before this development. The introduction of a dedicated child and adolescent psychiatric unit is expected to further improve consultation-liaison child psychiatric service delivery and research. I also expect that the understanding of the prevalence, pattern of presentation of mental disorders and management which is the specific objective of this study will help in improving the organisation of the new clinic.

\section{Methods}

\section{Study design and population}

The study was a descriptive, retrospective investigation that included all children and adolescents aged under 20 years seen at the Behavioural Sciences Department of UITH over a 5-year period whose case notes could be found.

\section{Location and background}

The UITH is located in the city of llorin in the north-central part of Nigeria; it serves as the psychiatric referral centre for Kwara state and four other adjoining states. Norin is inhabited mainly by the Yorubas, one of the major ethnic groups in Nigeria, and the indigenous people are predominantly Muslims.

The psychiatric unit of the hospital has a 20-bed facility for adults, and we hope to have 6 beds for children and adolescents in the proposed new unit (not in use yet). The existing unit is staffed by 8 consultant psychiatrists, 11 resident doctors, 17 nurses, a social worker, an occupational therapist, an electro-encephalography technologist and other support staff. It receives patients of various socio-economic backgrounds from the various clinical departments of the hospital, other government and private medical institutions, and institutions such as the social welfare centre, remand homes and schools; sometimes patients are brought directly to the clinics by relatives or refer themselves.

\section{Sampling}

The hospital numbers of the children and adolescents aged under 20 years were extracted from patients' registration registers of the psychiatric clinics, followed by retrieval of these case notes from the medical record library. No case notes were excluded, since it was obvious that because the notes were not standardised in structure or writing they would be at various levels of completeness.

\section{Data collection}

A pro forma was designed to assist in extracting information from the case notes on various aspects of socio-demographic, clinical and management characteristics of the patients. It included domains on developmental and educational history, family history, presenting symptoms, diagnostic classification and management, including follow-up visits.

\section{Data analysis}

The database was designed in the computer using EPI Info version 6. All variables were recoded and all data were entered and frequency tables obtained.

\section{Results}

\section{Socio-demographic characteristics}

A total of 94 children and adolescents representing both inpatient and outpatient individual cases were seen from January 2002 to December 2006. They represented 7\% of all new psychiatric cases (adults, children and adolescents) for this period, which totalled 1359 according to new patient registration records.

Tables I and II show some of the socio-demographic characteristics of the children and adolescents. There were $52 \%$ males and $48 \%$ females, and the age range was 7 - 19 years with a mean of 16.38 years (standard deviation (SD) 2.49 ); $17 \%$ were in the age group 7 - 13 years and $82 \%$ (the majority) in the age group 14 - 19 years. Only one child was aged under 7 years. Most of the children (79\%) had evidence of attending or having attended school, and the majority were in the appropriate class.

Sixty-seven per cent of the children were from monogamous families, in $68 \%$ of families there were 5 or more children, and $17 \%$ of the children had lost one or both parents. The majority of the parents were in a marriage, had at least primary school education and were engaged in at least a semiskilled job. Most of the children (91\%) lived with their parents. In only about 1 in 4 cases was there a family history of mental illness.

\section{Sources of referral}

Most of the patients (40\%) were referred from the general outpatient department of UITH, and $29 \%$ were referred from the internal medicine and paediatrics departments (Table III). In 39\% of cases the mother was the only informant, followed by both parents $(36 \%)$ and other relatives $(23 \%)$. 


\begin{tabular}{|c|c|c|}
\hline Variables & $n$ & $\%$ \\
\hline \multicolumn{3}{|l|}{ Gender } \\
\hline Male & 49 & 52 \\
\hline Female & 45 & 48 \\
\hline \multicolumn{3}{|l|}{ Age group (yrs) } \\
\hline $0-7$ & 1 & 1 \\
\hline $7-14$ & 16 & 17 \\
\hline $14-19$ & 77 & 82 \\
\hline \multicolumn{3}{|l|}{ Ethnic group } \\
\hline Yoruba & 82 & 87 \\
\hline Others & 12 & 13 \\
\hline \multicolumn{3}{|l|}{ Religion } \\
\hline Islam & 56 & 60 \\
\hline Christianity & 38 & 40 \\
\hline \multicolumn{3}{|l|}{ Educational status } \\
\hline In school & 74 & 79 \\
\hline Not in school & 20 & 21 \\
\hline \multicolumn{3}{|c|}{ Educational status - class at referral } \\
\hline Primary school & 12 & 13 \\
\hline Junior secondary school & 16 & 17 \\
\hline Senior secondary school & 30 & 32 \\
\hline Post-secondary school & 16 & 17 \\
\hline Not in school & 20 & 21 \\
\hline \multicolumn{3}{|l|}{$\begin{array}{l}\text { Educational status - is class } \\
\text { appropriate? }\end{array}$} \\
\hline Yes & 55 & 59 \\
\hline No & 19 & 20 \\
\hline Not in school & 20 & 21 \\
\hline \multicolumn{3}{|c|}{$\begin{array}{l}N=\text { number of people in the study population } n=\text { number of people in th } \\
\text { sample population affected by the variable } \%=\text { percentage of } n / N \text { to th } \\
\text { nearest whole number. }\end{array}$} \\
\hline
\end{tabular}

\section{Presenting symptoms}

The most frequent presenting symptoms and complaints were irrational talk and behaviour, characterised by talking gibberish or excessively, talking out of context and talking to self. Auditory hallucinations, with a second person commenting on or a third person discussing the patient, were also experienced by some of the patients with schizophrenia. Other common presenting symptoms included sleep disturbance, mainly insomnia, and violent or aggressive behaviour to self or others. A few patients presented with a history of recurrent episodes of seizures.

\section{Diagnosis and management}

The most common diagnosis was schizophrenia (50\%), followed by acute organic brain syndrome (delirium) (15\%) and seizure disorders (9\%) (Table III). Cases of delirium were usually associated with infections and malaria.

In a retrospective study of this nature it can be expected to find diagnoses recorded and classified in different ways because of

\begin{tabular}{|c|c|c|}
\hline Variables & $n$ & $\%$ \\
\hline \multicolumn{3}{|l|}{ Type of family } \\
\hline Monogamy & 60 & 64 \\
\hline Polygamy & 24 & 26 \\
\hline Special families & 6 & 6 \\
\hline Not documented & 4 & 4 \\
\hline \multicolumn{3}{|l|}{ No. of children in family } \\
\hline $0-4$ & 29 & 31 \\
\hline$\geq 5$ & 63 & 67 \\
\hline Not documented & 2 & 2 \\
\hline \multicolumn{3}{|l|}{$\begin{array}{l}\text { Any family history of mental } \\
\text { illness? }\end{array}$} \\
\hline Yes & 70 & 74 \\
\hline \multicolumn{3}{|l|}{ No } \\
\hline \multicolumn{3}{|l|}{ Is any parent dead? } \\
\hline Yes & 14 & 15 \\
\hline No & 80 & 85 \\
\hline \multicolumn{3}{|l|}{ Parental marital status } \\
\hline In a marriage & 71 & 76 \\
\hline Not in a marriage & 23 & 24 \\
\hline \multicolumn{3}{|l|}{ Who has custody of the child? } \\
\hline Parents & 86 & 91 \\
\hline Relatives & 6 & 7 \\
\hline Social welfare institutions & 2 & 2 \\
\hline \multicolumn{3}{|l|}{ Mother's educational status } \\
\hline None & 18 & 19 \\
\hline Primary & 26 & 28 \\
\hline$\geq$ secondary & 26 & 28 \\
\hline Not documented & 24 & 25 \\
\hline \multicolumn{3}{|l|}{ Father's educational status } \\
\hline None & 16 & 17 \\
\hline Primary & 23 & 25 \\
\hline$\geq$ secondary & 32 & 34 \\
\hline Not documented & 23 & 24 \\
\hline \multicolumn{3}{|l|}{ Mother's occupational status } \\
\hline Skilled & 25 & 27 \\
\hline Semi-skilled & 25 & 27 \\
\hline Unskilled & 21 & 22 \\
\hline Not documented & 23 & 24 \\
\hline \multicolumn{3}{|l|}{ Father's occupational status } \\
\hline Skilled & 28 & 30 \\
\hline Semi-skilled & 30 & 32 \\
\hline Unskilled & 13 & 14 \\
\hline Not documented & 23 & 24 \\
\hline \multicolumn{3}{|c|}{$\begin{array}{l}N=\text { number of people in the study population who responded } n=\text { number of } \\
\text { people in the sample population affected by the variable } \%=\text { percentage } \\
\text { of } n / N \text { to the nearest whole number 'Special families' = children with a single } \\
\text { parent or those living with relatives. }\end{array}$} \\
\hline
\end{tabular}

the varied backgrounds of psychiatrists, especially in the absence of enforceable protocols. The ICD 10 classes of the diagnoses have been included to achieve some degree of uniformity. 


\begin{tabular}{|c|c|c|}
\hline Variables & $n$ & $\%$ \\
\hline \multicolumn{3}{|l|}{ Source(s) of referral } \\
\hline General outpatient department of UITH & 40 & 43 \\
\hline Paediatrics department of UITH & 5 & 5 \\
\hline Internal medicine department of UITH & 22 & 23 \\
\hline Private hospitals & 10 & 11 \\
\hline Social welfare institutions & 3 & 3 \\
\hline Parents/relatives & 14 & 15 \\
\hline \multicolumn{3}{|l|}{ Diagnostic classifications } \\
\hline Schizophrenia (F20.0, 1, 3, 9) & 47 & 50 \\
\hline Delirium (F05, F06) & 14 & 15 \\
\hline Seizure disorders $(G 40.2,3,6)$ & 8 & 9 \\
\hline Manic episode (F30) & 5 & 5 \\
\hline Depressive episode (F32) & 3 & 3 \\
\hline Anxiety disorders (F41, F42) & 5 & 5 \\
\hline Mental and behavioural disorder due to cannabinoid $(F 12.00,04)$ & 3 & 3 \\
\hline Acute and transient psychotic disorders (F23) & 6 & 7 \\
\hline Conduct disorders (F91) & 2 & 2 \\
\hline Mental retardation (F71) & 1 & 1 \\
\hline \multicolumn{3}{|l|}{ Place of management } \\
\hline Inpatient & 34 & 36 \\
\hline Outpatient & 60 & 64 \\
\hline \multicolumn{3}{|l|}{ Mode of management } \\
\hline Involving drugs & 81 & 86 \\
\hline Not involving drugs & 13 & 14 \\
\hline \multicolumn{3}{|l|}{ Type of drug management ( $N=81$ ) } \\
\hline Involving use of antipsychotic & 76 & 94 \\
\hline Not involving use of antipsychotic & 5 & 6 \\
\hline \multicolumn{3}{|l|}{ Drug combinations used $(N=81)$} \\
\hline Antipsychotic with anticholinergics & 61 & 75 \\
\hline Antipsychotic with antidepressants & 6 & 7 \\
\hline Antipsychotic with anticonvulsant & 7 & 9 \\
\hline Antipsychotic with other combinations & 2 & 2 \\
\hline Other combinations without antipsychotics & 5 & 6 \\
\hline \multicolumn{3}{|l|}{ Outcome } \\
\hline Improved & 72 & 77 \\
\hline No improvement & 5 & 5 \\
\hline Defaulted first follow-up & 17 & 18 \\
\hline
\end{tabular}

In terms of place of management, $64 \%$ were treated as outpatients and $36 \%$ as inpatients. Drug therapy was involved in the overwhelming majority of cases (98\%). The most frequently prescribed medications were the antipsychotics (94\%), of which haloperidol was the most frequently prescribed (62\%), atypical antipsychotics such as risperidone being used in only $8 \%$ of cases. The most common combination of drugs was antipsychotic with anticholinergics (75\%). Amitriptyline was the antidepressant most frequently used and carbamazepine and diazepam were the anticonvulsants most frequently used, although not for their anticonvulsive function alone. There was no case in which electroconvulsive therapy (ECT) was used. 
In terms of management outcome, the majority of patients treated $183 \%$ improved at least initially, but records of extended followup visits were inadequate to allow for assessment of long-term outcome, probably because of poor clinic attendance rates.

\section{Discussion}

The present review of 94 child and adolescent psychiatric cases over a 5-year period supports previous observations that hospital child psychiatry cases are still scarce. A closer look at the age distribution reveals that young children were rarely seen; only one patient was aged under 7 years, and only $17 \%$ were less than 14 years old; the mean age was 16.38 years (SD 2.49). With various epidemiological studies in Nigeria ${ }^{5-8}$ suggesting a prevalence of child psychiatric disorders in the range of $9.6-19.6 \%$ in our population, the apparently low proportion of younger children in this study is remarkable. Since many of the children in some previous community and primary care studies ${ }^{5-8}$ had emotional and conduct disorder diagnoses, it would have been expected that these disorders will be well represented in the present study, but only 7 children had either problem.

This pattern of prevalence is in agreement with previous studies $^{5-8,15}$ and suggests that low attendance at hospital child psychiatric services persists; especially with regard to emotional and conduct disorders, which are known to constitute the bulk of mental health disorders in children. Under-recognition and/or under-reporting of these problems have been blamed for this scenario.

The under-recognition and under-reporting of mental health problems and subsequent low attendance at hospital child psychiatric services have been attributed to several factors mentioned earlier. These include inadequate health care resources, ignorance on the part of patients/parents and health care providers, restrictive cultural practices, superstition and stigma surrounding mental illness, poverty, and shortage of specialised personnel. 9,12,14-19

Few cases of brain damage were found in this review, compared with an earlier study of children aged $2-15$ years $^{12}$ in another centre. This is because the children in that study were younger, $60.6 \%$ being under 13 years of age, whereas in the present study only $18 \%$ were under 14 years of age and the mean age was 16.38 years. Many of the patients with brain damage in that review were suspected to have had severe intracranial infections, postnatal brain injuries and febrile convulsions. ${ }^{12}$ In interpreting the pattern in the current study it is possible that the lack of a dedicated child psychiatric unit in the hospital could have removed the incentive to refer this group of patients to the psychiatrist, especially if there were no severe behavioural disturbances.

Since the majority of patients in this study were in the age group 14 - 19 years, it was not surprising that schizophrenia was the most common diagnosis; this is similar to the findings of another study in this same setting. ${ }^{14}$ The onset of most forms of schizophrenia is usually during late adolescence or early adulthood. ${ }^{1,3,4}$

The majority of our patients were living with their parents in monogamous families, suggesting some degree of family stability and functioning, especially when one also considers that most of the parents had some formal education and were socioeconomically productive in jobs.

In this type of socio-economic environment it should be feasible to obtain the family support needed to get a good outcome from treatment.

Most of the presenting symptoms were those of psychosis, which is not surprising in view of schizophrenia being the most common diagnosis. This has made us highly aware of the need to make adequate preparation for dealing with disruptive situations in the new unit, especially with regard to types of restraints and handling of distressed families. Drug therapy, particularly antipsychotics, dominated the management approach, obviously because psychosis was the most common diagnosis. It is, however, important to note that despite this no patient had ECT. This modality of treatment is not commonly used in child and adolescent psychiatry, except in very severe cases of depression, ${ }^{4}$ and in this study no patient with depression had a severe enough episode to warrant it.

All the children were managed in adult facilities, as no dedicated facilities for children existed at the time. The fact that most of the children had adult-type disorders could in part have been due to facility-imposed selection. A dedicated unit with childfriendly facilities and staff would attract referrals from relevant departments. An increase in the number of cases seen and better clinic attendance has the potential to improve quantity and quality of care and research.

The well-co-ordinated referral systems in developed countries mentioned earlier, which ensure that the majority of children with problems are brought under orthodox care, are still absent in Nigeria. Most of our patients were referred from the primary care-associated disciplines of the hospital. To improve hospital attendance by children, good working relationships with primary 
care physicians are essential and should be encouraged. It is hoped that the introduction of a dedicated child and adolescent psychiatric unit will enhance this objective.

In view of the extremely few referrals from social welfare workers and institutions, and the fact that there were none at all from teachers, school counsellors, schools or corrective institutions/ remand homes, the new unit has planned a series of outreach programmes to educate and encourage them to identify and refer cases, and similarly establish a consultation-liaison relationship.

To ensure over the long term that the newly established unit provides better delivery of child psychiatric services, in terms of both demand and supply, we need education of parents, children, institutions, physicians and health care providers at all levels of health care to improve identification and referral of cases. This could be achieved through direct contact, workshops, seminars and conferences or through the various media of communication.

In the short term the new unit will try to encourage the various departments in the hospital that deal with children to recognise and refer cases; and to establish a consultation-liaison relationship. Equally important and challenging is the acquisition of the necessary infrastructure, clinical, educational and physical, which will improve services by attracting and properly treating cases.

\section{Conclusion}

Hospital attendance of children and adolescents for psychiatric disorders in Ilorin is still relatively poor. Accordingly the number of children with psychiatric disorders presenting to the psychiatrist in the hospital is low despite a reported high prevalence in the society.

The establishment of a dedicated child and adolescent psychiatric facility in Ilorin is expected to improve services, training and research and by extension hospital attendance and patient care. Liaison psychiatry with primary care physicians and institutions concerned with the care of children remains vitally important in achieving these objectives.

\section{References}

1. Barker P. Basic Child Psychiatry. 6th ed. Cambridge: Blackwell Science, Cambridge University Press, 2000.

2. Rutter M, Tizard J, Yule W, et al. Isle of Wight Studies 1964-1974. Psychol Med $1976 ; 6: 313-332$.

3. Kaplan HI, Sadock BJ, eds. Synopsis of Clinical Psychiatry: Behavioural Sciences/ Clinical Psychiatry. 9th ed. Baltimore, Md: Lippincott Williams \& Wilkins, 2002: $1128-1136$.

4. Gelder M, Harrison P, Cowen P, eds. Shorter Oxford Textbook of Psychiatry. New York: Oxford University Press, 2006: 280, 305, 649-697

5. Adelekan ML, Ndom RJE, Ekpo M. Epidemiology of child behavioural disorders in Ilorin, Nigeria - Findings from parental reports. West Afr J Med 1999; 18(1): 39-48.

6. Ohaeri JU, Odejide OA, Gureje O, Olatawura MO. Psychiatry morbidity among children attending health facilities in primary health care in a rural Nigeria community Niger Med J 1994; 26 (3): 93-95.

7. Gureje $\bigcirc$, Omigbodun $\bigcirc \bigcirc$, Grater R, Acha RA, Ikuesan BA, Morris J. Psychiatric disorders in a paediaric primary clinic. Br J Psychiatry 1994; 165: 527-530.

8. Abiodun OA. Emotional illness in a paediatric population in Nigeria. J Trop Paediatr 1993; 39: 49-51

9. Makanjuola JDA. Paediatric psychiatry at the neuro-psychiatric hospital Aro, Abeokuta, Nigeria - a five year review. West Afr J Med 1987; 6 (3): 185-191.

10. Rutter M, Graham P, Birch HG. A Neuropsychiatric Study of Childhood. London: Heinemann, 1970

11. Tanguay PE, Cantor SL. Schizophrenia in children: Introduction. J Am Acad Child Psychiatry 1986; 25: 591-594.

12. Olatawura MO, Dejide AO. Child psychiatric disorders in Ibadan. Niger J Paediatrics 1976; 3(1): 9-14.

13. Olatawura MO. The paediatrician and child psychiatry in Nigeria. Niger $\rfloor$ Paediatrics 1974;1 (2): 65-68

14. Oyewumi LK. Inpatient adolescent psychiatry in a teaching hospital in Nigeria. Acta Psychiatr Scand 1989; 80: 639-643.

15. Swift CR, Asuni T, eds. Mental Health and Disease in Africa: With Special Reference to Africa South of the Sahara. Medicine in the Tropics series. London: Churchill Livingstone, 1975.

16. Adelekan ML. Psychiatric disorders of children and young adults in developing countries. In: Tantam D, Appleby L, Duncan A, eds. Psychiatry for the Developing World. London: Royal College of Psychiatrists, 1995: 31 1-340.

17. Olatawura MO. Mental health services for children in African region. Int J Mental Health 1978; $7(1): 34-38$.

18. Odejide AO, Oyewumi LK, Ohaeri JU. Psychiatry in Africa: An overview. Am J Psychiatry 1989; 146: 708-716.

19. Oladimeji BY. Problems and prospects of child mental health research in Nigeria. Ife Psychologia 1996; 4 (2): 22-34

20. Olarewaju DM. Complications of sickle cell anaemia - a review. Niger Med Practitioner 1988; 16(3): 107-111. 